\title{
Storing, Maintaining and Mobilizing Botswana National Museum's Entomology Digital Collections: The GBIF/BID Approach
}

\author{
Boikhutso Lerato Rapalai ‡ \\ ‡ Botswana National Museum, Gaborone, Botswana
}

Corresponding author: Boikhutso Lerato Rapalai (blmokotedi13@gmail.com)

Received: 01 May 2018 | Published: 15 Jun 2018

Citation: Rapalai B (2018) Storing, Maintaining and Mobilizing Botswana National Museum's Entomology Digital Collections: The GBIF/BID Approach. Biodiversity Information Science and Standards 2: e26328.

https://doi.org/10.3897/biss.2.26328

\begin{abstract}
The Botswana National Museum is mandated to protect, preserve and promote Botswana's cultural and natural heritage for sustainable utilization thereof by collecting, researching, conserving and exhibiting for public education and appreciation. The Entomology Section of the museum is aiming towards becoming the national center for entomology collections as well as contributing to the monitoring and enhancement of natural heritage sites in Botswana. The Botswana National Museum entomology collection was assembled over more than three decades by a succession of collectors, curators and technical officers. Specimens are carefully prepared and preserved, labelled with field data, sorted and safely stored. The collection is preserved as wet (ethanol preserved) or as dry pinned specimens in drawers. This collection is invaluable for reference, research, baseline data and educational purposes.
\end{abstract}

As a way of mobilizing insect biodiversity data and making it available online for conservation efforts and decision making processes, in 2016 the Botswana National Museum collaborated with five other African states to implement the Biodiversity Information for Development (BID) and Global Biodiversity Information Facility (GBIF) funded African Insect Atlas' Project (https://www.gbif.org/project/82632/african-insectatlas). This collaborative project was initiated to move biodiversity knowledge out of select 
insect collections into the hands of a new generation of global biodiversity researchers interested in direct outcomes. To date, the Botswana National Museum has been instrumental through the efforts of this project in storing, maintaining and mobilizing insect digital collections and making the data available online through the GBIF Platform.

\section{Keywords}

data mobilization, digital, entomology, collections, biodiversity,

\section{Presenting author}

Boikhutso Lerato Rapalai 